\title{
Numerical and experimental study of the formation of adiabatic shear band
}

\author{
D.-T. Chung, S.-K. Moon and Y.-H. Yoo \\ Advanced Technology and Research Center, Agency for Defense Development, P.O. Box 35 , \\ Taejon 305-600, Korea
}

\begin{abstract}
Résumé: Pour étudier l'initiation et la croissance des bandes de cisaillement adiabatique lors d'un chargement par choc, nous avons choisi d'utiliser une éprouvette en forme de chapeau. Un code aux éléments finis avec intégration temporelle explicite et un modèle de comportement du matériau dépendant de la vitesse de déformation plastique ont été utilisés pour l'étude numérique. Le modèle prend en compte les effets de l'écrouissage et de l'adoucissement thermique. pour la partie expérimentale, nous avons utilisé des échantillons en acier 4340 et une barre d'Hopkinson en compression permettant d'appliquer des pulses de compression contrôlés. Après le chargement, les échantillons ont été coupés, polis, attaqués et examinés par microscopie optique. Nous avons observé des bandes de cisaillement très nettes apparemment formées par une déformation localisée. On montre que la forme générale et la direction des bandes de cisaillement adiabatique coïncident avec les résultats des calculs numériques.
\end{abstract}

\begin{abstract}
The stepped specimen under impact loading was chosen to study the initiation and growth of the adiabatic shear band. Explicit time integration finite element code with rate dependent plasticity material model was utilized for numerical study. The material model includes the effects of strain hardening, strain rate hardening, and thermal softening. For experimental study, specimen made of 4340 steel and compression Hopkinson's bar was used to apply controlled short compression pulse. After the impact loading, the specimen was cut, polished, etched, and examined under the optical microscope. Very sharp shear band apparently formed by localized deformation was observed. It is shown that overall shape and direction of adiabatic shear band coincide with results of the numerical calculation.
\end{abstract}

\section{INTRODUCTION}

Unlike quasi-static deformation adiabatic shear band at high strain-rate deformation occurs as a result of thermally induced instability. Also adiabatic shear band usually lead to fracture either in ductile or brittle manner. Lots of work has been done to study the initiation and growth of shear bands theoretically, experimentally, and numerically $[1-7]$.

Most theoretical work on the initiation of shear bands is limited to quasi-static deformation where thermal softening is less significant than other mechanisms which can produce instability by localized deformation [1]. It is very hard to estimate analytically the growth behavior of the band due to severe deformation with large rotation. On the other hand, the finite element method with explicit time integration and isoparametric quadrilateral elements with one point integration is considered appropriate for the study of the overall behavior of adiabatic shear bands. Although the code seems to be an effective tool for studying the evolution of adiabatic shear bands, a thorough knowledge of the mechanical behavior of the material, macroscopically and microscopically, is critically needed ${ }^{[8,9]}$. Carefully designed experiments could verify the fidelity of the numerical simulation. 
In this work, a specially designed 'stepped' specimen that resembles a top hat is chosen to study the initiation and growth of adiabatic shear bands and the final fracture. The specimen made of 4340 steel underwent various heat treatments to achieve the prescribed mechanical properties. The split Hopkinson's pressure bar was used to apply a controlled short impact load to the specimen. The specimen was sectioned and prepared for optical examination. Then an explicit time integration finite element code based on PRONTO-2D ${ }^{10]}$ incorporatiing a visco-plasticity model which includes the effects of strain hardening, strain-rate hardening and thermal softening was utilized to simulate the impact of the stepped specimen. Experimental and numerical results were then compared.

\section{EXPERIMENT}

\subsection{Specimen Preparation}

A schematic drawing of the 'stepped' specimen with deformation controlling ring is shown in Fig. 1. The specimen, made of 4340 steel with ESR(Electro Slag Remelting) grade, was machined first. Then it underwent (1) austenizing at $845^{\circ} \mathrm{C}$ for $15 \mathrm{~min}$, (2) oil quenching, (3) tempering at $565^{\circ} \mathrm{C}$ for 1 hour and (4) oil quenching. After the heat treatment a series of mechanical test were done to measure the necessary mechanical properties. These are tabulated in Table 1 and were used for the numerical calculation in the next section.

\subsection{SHPB( Split Hopkinson's Pressure Bar ) Test}

The specimen was placed between the incident and the transmit bar of the SHPB which were made of maraging steel. To minimize the effect of friction, $\mathrm{MoS}_{2}$ was applied to the interface between the specimen and the bars. The shortest striker bar available, $64 \mathrm{~mm}$ long and $14.8 \mathrm{~mm}$ in diameter, was fired from a $30 \mathrm{~mm}$ bore air gun at $50 \mathrm{~m} / \mathrm{sec}$. Even with the shortest striker, the specimen underwent total plugging failure after full growth of the shear band. Rings with various heights were used to stop the growth of the adiabatic shear band. It was found that a ring of $4.35 \mathrm{~mm}$ height was the optimum.

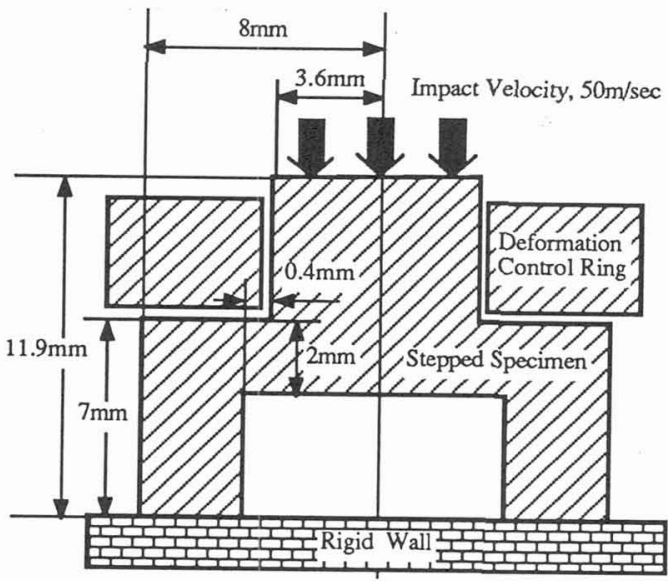

Fig. 1: Schematic drawing of stepped specimen.

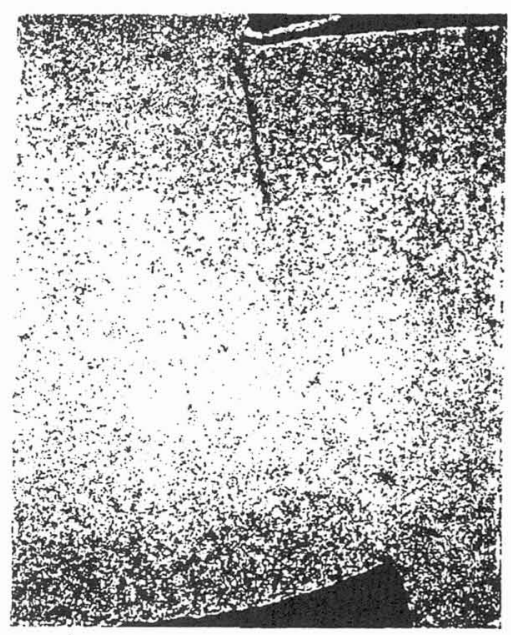

Fig. 2: Optical micrograph of adiabatic shear band.

\subsection{Experimental Results}

After an impact, using a deformation control ring of $4.35 \mathrm{~mm}$ in thickness, the specimen was reduced from $11.9 \mathrm{~mm}$ to $11.6 \mathrm{~mm}$ in height. This difference between the height of the ring and the overall height reduction was due to elastic unloading after the impact. Other than the height reduction, no apparent change of overall shape was noticed. After the impact, the specimen was sectioned, mounted, polished, and etched for microscopic observation. 
A well grown band from the upper corner toward the lower corner was observed and is shown in Fig. 2. No shear band starting from the lower corner was observed. So the growing direction of the adiabatic shear band was from the upper corner toward the lower corner. As shown in Fig. 2 a macro crack at the upper corner was observed. This was first considered a machining or quenching crack. After careful microscopic study, however, it was found that the crack was formed due to folding resulting from the abrupt growth of adiabatic shear band.

The white shear band which indicates a phase transformation from austenite to martensite due to adiabatic heating was not found. A deformation concentrated shear band was observed instead.

\section{NUMERICAL SIMULATION}

\subsection{Explicit Finite Element Method: Improved algorithm}

In an explicit time integration finite element code the equations of motion are integrated at each time step to obtain the velocity gradient. The constitutive algorithm then employs this velocity gradient and produces the stress increment and the increment in the plastic deformation, the temperature, and the involved internal state variables, over the time increment generally specified by the code. A basic requirement of an efficient constitutive algorithm, therefore, is to calculate all necessary incremental quantities accurately, in any time increment specified by the large-scale code. This issue has been addressed by many investigators ${ }^{[7]}$ but most of the methods based on second-order or higher correction of the current tangent moduli, ineffective for high-strain, high-strain-rate dynamic computation where localized deformations produce abrupt changes in plastic flow regimes.

In this study an improved algorithm developed by one of the authors ${ }^{[11]}$ was implemented into an explicit dynamic code, based on PRONTO-2D[9]. This method is explicit and simple. It is stable and produces near-exact solutions. This algorithm is based on the simple observation that elastic-viscoplastic deformation of virtually all ductile materials includes only a small elastic part. Therefore, at the beginning of each time increment prescribed by the computer code, the scalar measure of total deformation rate can be approximated, with little error, to be due to viscoplasticity. The error produced by this assignment is then estimated and corrected, with the aid of constitutive relations. One should refer to [11] for detailed explanations.

\subsection{General Results}

Fig. 3 shows the typical shape of the undeformed mesh for numerical simulation. More fine elements, $50 \mu \mathrm{m}$ square, were placed between the upper and the lower hollow cylinder where most of the severe deformation would take place. Only the right half was considered because of axi-symmetry about the z-axis. A constant z-directional velocity of $50 \mathrm{~m} / \mathrm{sec}$ was prescribed along the top surface and a rigid surface contact condition was assumed along the bottom surface. It was also assumed that there is no friction along the top and bottom surfaces. No heat conduction across the elements was allowed because of the adiabatic assumption and $85 \%$ of the plastic work was assumed to be converted into the intemal heat.

Numerical calculation was carried out for $\mathrm{t} \leq 10 \mu \mathrm{sec}$. Fig. 4 shows the deformed shape of the stepped specimen at $\mathrm{t}=6 \mu \mathrm{sec}$. The top surface of the specimen moved $0.3 \mathrm{~mm}$ downward. Slight mushrooming took placed at the top region due to the inertia effect. Severe deformation is concentrated

Table 1. Material Coefficients for computations

\begin{tabular}{|ll|}
\hline \multicolumn{1}{|c|}{$\begin{array}{l}\text { Elastic visco-plasticity } \\
\text { thermal softening } \\
\text { material model }\end{array}$} & $\sigma_{\mathrm{Y}}=\sigma_{\mathrm{o}}\left(1+\frac{\varepsilon^{\mathrm{p}}}{\varepsilon_{\mathrm{o}}}\right)^{\mathrm{N}}\left(\frac{\dot{\varepsilon}^{\mathrm{P}}}{\dot{\varepsilon}_{\mathrm{o}}}\right)^{1 / \mathrm{m}} \operatorname{Exp}\left[\lambda\left(\mathrm{T}_{\mathrm{o}}-\mathrm{T}\right)\right]$ \\
\hline Young's modulus $\mathrm{E}=210 \mathrm{Gpa}$ & Poisson's ratio $\mathrm{v}=0.29$ \\
Density $\rho=7.8 \mathrm{~g} / \mathrm{cm}^{2}$ & Thermal softening Coef. $\lambda=0.0013 \rho^{\circ} \mathrm{C}$ \\
Initial yield stress $\sigma_{\mathrm{o}}=1.03 \mathrm{Gpa}$ & Reference strain $\varepsilon_{\mathrm{o}}=0.0049$ \\
Strain hardening exponent $\mathrm{N}=0.005$ & Reference strain-rate $\dot{\varepsilon}_{\mathrm{o}}=1 \times 10^{6} / \mathrm{sec}$ \\
Strain-rate hardening exponent $\mathrm{m}=167$ & Initial temperature $\mathrm{T}_{\mathrm{o}}=0^{\circ} \mathrm{C}$ \\
\hline
\end{tabular}


within the narrow zone near the upper corner accompanied by folding. The deformation sequences are depicted in Fig. 5. Only horizontal lines are drawn for clarity.

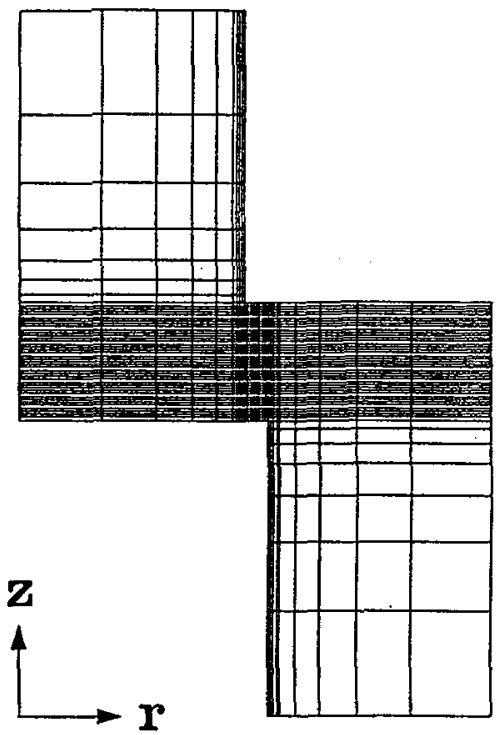

Fig. 3: Undeformed mesh.

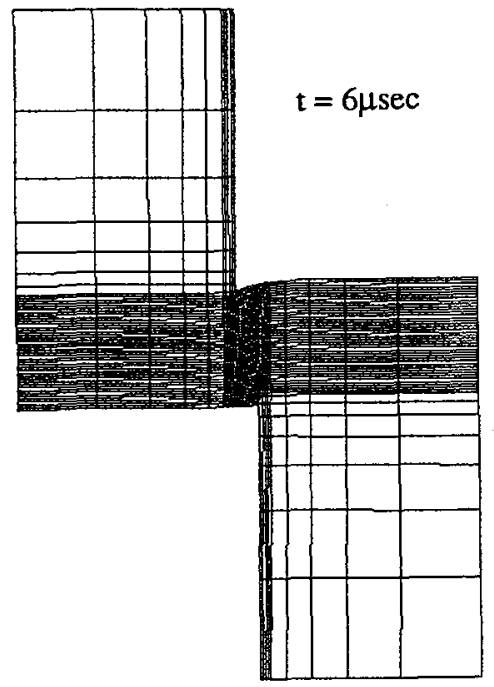

Fig. 4: The deformed mesh.
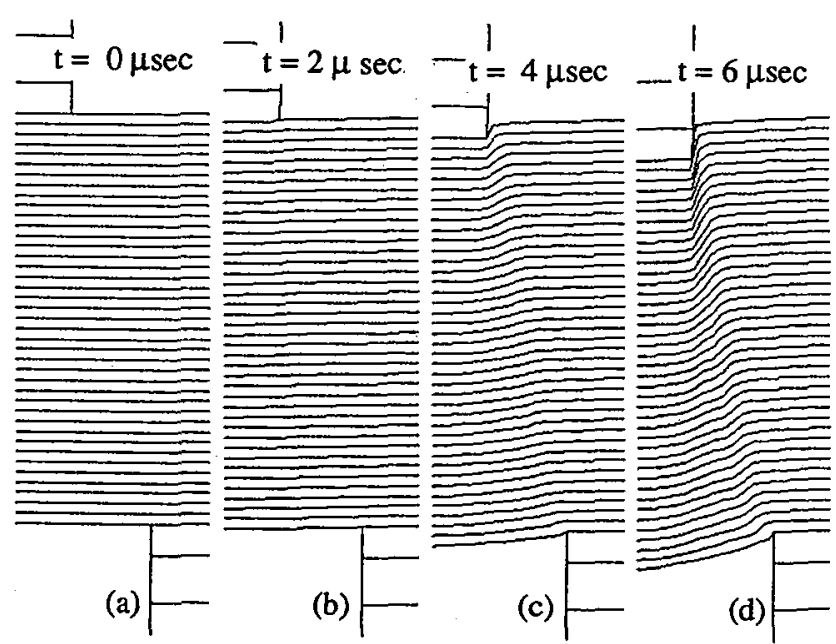

Fig. 5: Close up view of the deformed mesh.

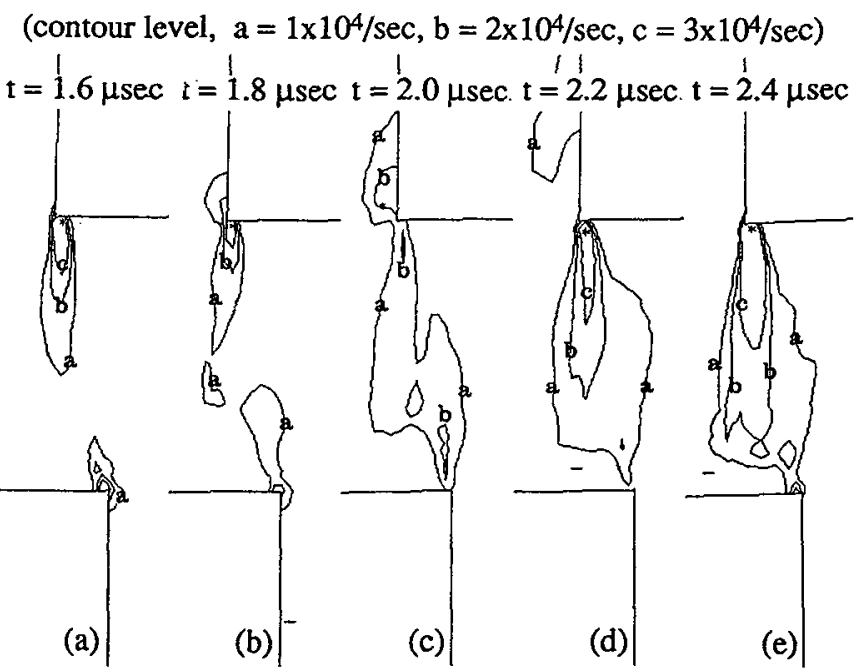

Fig. 6: Contours of equivalent plastic strain-rate.

\subsection{Mechanism of Initiation}

In this study contours of equivalent plastic strain-rate rather than those of von Mines stress or plastic strain were closely monitored. Equivalent plastic strain-rate is negligible when the level of von Mises stress is below the flow stress but attains a large value once the level of von Mises stress is close to the flow stress, i.e. a slight change of von Mises stress is amplified into an equivalent plastic strain-rate change. This makes equivalent plastic strain-rate a good indicator to detect the initiation of the adiabatic 
Table 2. Time history of max. von Mises and max. equivalent plastic strain-rate

\begin{tabular}{|l|r|r|r|r|r|r|r|c|}
\hline Time $(\mu \mathrm{sec})$ & 1.4 & 1.6 & 1.8 & 2.0 & 2.2 & 2.4 & 2.6 & 2.8 \\
\hline $\begin{array}{l}\text { Max. von Mises stress } \\
(\mathrm{GPa})\end{array}$ & 1.102 & 1.101 & 1.097 & 1.096 & 1.098 & 1.099 & 1.100 & 1.102 \\
\hline $\begin{array}{l}\text { Max. equivalent plastic } \\
\text { strain-rate(x 106/sec) }\end{array}$ & 0.059 & 0.063 & 0.037 & 0.025 & 0.049 & 0.107 & 0.158 & 0.183 \\
\hline
\end{tabular}

shear band. This is still effective even when thermal softening due to adiabatic heating prevails.

The dynamics of the equivalent plastic strain-rate development for the rate-dependent, or viscoplastic, solid is shown in Fig. 6. Equivalent plastic strain-rate contours originate at the upper corner and evolve as fingerlike contours pointing downward. Then another contour emanates from the lower corner in the upwards direction. Once these contours meets in the middle, at around $t=2 \mu \mathrm{sec}$, the maximum value of the contours drops sharply, from $6 \times 10^{4} / \mathrm{sec}$ to less than $2 \times 10^{4} / \mathrm{sec}$. The maximum occurs outside and slightly above the corner, see Fig. 6(c). The time history of the equivalent plastic strain-rate and the von Mises stress are tabulated in Table 2. The sudden drop of the equivalent plastic strain-rate and of the von Mises stress is considered as a pre-cursor of the initiation of the adiabatic shear band. The direction and the path of the future band are considered to be determined at this stage.

The equivalent plastic strain-rate then starts to increase rapidly from the upper corner within the zone defined above accompanied by a corresponding increase in equivalent plastic strain. Thermal softening then takes place to cause a sharp localization of deformation, Fig. 7.

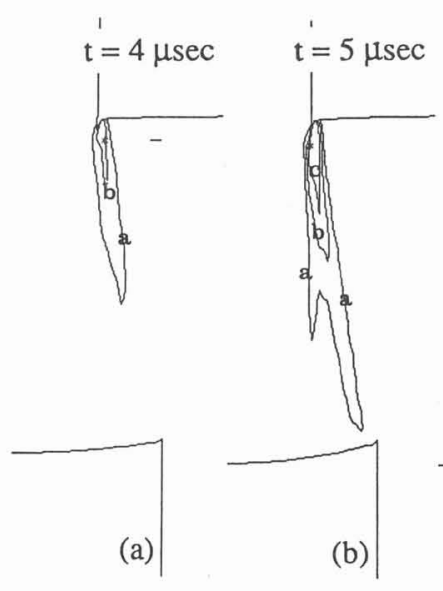

Fig. 7: Contours of equivalent plastic strain-rate.

Fig. 9: Profile of the fractured specimen.

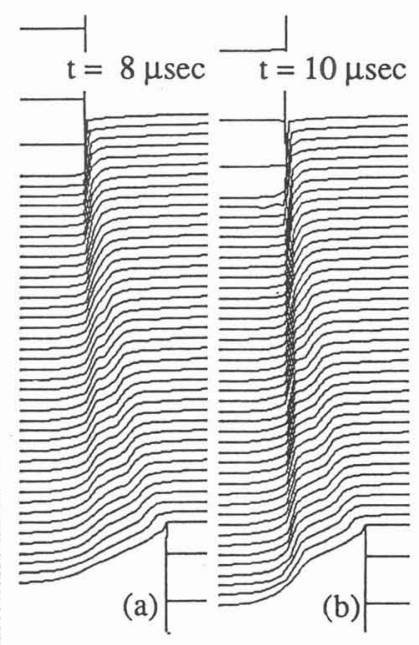

Fig. 8: Close up view of the deformed mesh.

\subsection{Change of Growth Direction}

In the experiment, the growth of the adiabatic shear band was frozen by the deformation control ring. It was observed that the direction of the band was from the upper corner toward the lower corner, Fig. 3. This coincides perfectly with the numerical result, shown in Fig. 7. It is quite interesting to examine the numerical results for the dynamics of the adiabatic shear band growth. After full growth of the band another band with a different direction starts to grow out from the upper corner, at about $t=5$ 
$\mu \mathrm{sec}$, see Fig. 7(b). A clearly distinguishable second deformation band is formed at about $t=8 \mu \mathrm{sec}$, Fig. 8(a). This runs in a vertical direction and continues to grow, see Fig. 8(b). Thus a bifurcation occurs in the growth direction of the band. This is a discrepancy with the experimental result.

Fig. 9 shows the profiles of a plugged out specimen. It is clear that the specimen experienced total failure along the path of the first adiabatic shear band. No evidence of the second shear band was found. One could conclude that the material within the adiabatic shear band degenerates much faster than expected. The constitutive relation for the numerical calculation did not include ductile or brittle failure criterion. Hence failure modeling based on microscopic examination is essential for simulating the final failure mode correctly. It is very interesting to see the result with different heat treatment conditions, i.e. with different hardness and ductility. These are planned for future study.

\section{CONCLUSION}

After the impact experiment on the stepped specimen and the corresponding numerical simulation using an explicit finite element code one could conclude as follows:

(1) Except for the final failure mode, the finite element calculation simulates the impact experiment very accurately.

(2) The width of the adiabatic shear band was about $10 \mu \mathrm{m}$.

(3) The final fracture path coincides with that of the first adiabatic shear band.

(4) A failure criterion based on micro structure and/or phase transformation is needed.

(5) Experiments with specimens of different hardness and ductility are needed.

\section{Acknowledgment}

The authors with to thank Dr. D.-H. Baik(A.D.D.) for careful specimen preparation for the test and for the postmortem study and valuable suggestions.

\section{REFERENCES}

Books:[1] Rice J.R., "The Localization of Plastic Deformation", (Theor. \& Appl. Mech., W.T. Koiter(ed.), North Holland Publishing Co., 1976) pp.207-220.

Periodicals:[2] Rogers H.C., "Adiabatic Plastic Deformation", Ann. Rev. Mat. Sci. 9 (1979) pp. 283-311.

Periodicals:[3] Asaro R.J., "Material Modelling and Failure Modes in Metal Plasticity", Mech. of Mats. 4 (1985) pp. 343-373.

Periodicals:[4] Timothy S.P., "The Structure of Adiabatic Shear Band in Metals: A Critical Review", Acta Metall. 35 (1987) pp. 301-306.

Periodicals:[5] Needleman A., "Dynamic Shear Band Development in Plane Strain", J. Appl. Mech. 56 (1989) pp.527-534.

Periodicals:[6] Chou P.C., Hashemi J., Chou A., and Rogers H.C., "Experimentation and Finite Element Simulation of Adiabatic Shear Band in Controlled Penetration Impact", Int. J. Impact Engng. 11, No. 3 (1991) pp.305-321.

Periodicals:[7] Pierce D., Asaro R.J., and Needleman A., "Material Rate Dependence and Localized Deformation in Crystalline Solids", Acta Metall. 32 (1983) pp. 1951-1976.

Conference Proceedings:[8] Johnson G.R. and Cook W.H., "A Constitutive Model and Data for Metals Subjected to Large Strain Rates and High Temperatures", 7th Int. Symp. on Ballistics, The Hague, The Netherlands, (1983) pp.541-547.

Periodicals:[9] Zerilli F.J. and Armstrong R.W., "Dislocation-Mechanics-Based Constitutive Relations for Material Dynamics Calculation", J. Appl. Phys. 61 (1987) pp.1816-1825.

Reports: [10] Taylor L.M. and Flanagan D.P., PRONTO 2D, A Two-Dimensional Transient Solid Dynamics Program (SAND86-0594 Sandia National Laboratories, Albuquerque, NM 1987).

Periodicals: [11] Nemat-Nasser S. and Chung D.-T., "An Explicit Constitutive Algorithm for LargeStrain, Large-Strain-Rate Elastic-Viscoplasticity", Comp. Mech. Appl. Mech. 95 (1992) pp.205-219. 